\title{
Open or Closed Stacks?
}

Mr. Hicks was formerly librarian, Western State College, Gunnison, Colorado.

\begin{abstract}
A GENERALLY ACCEPTED PRINCIPLE in American college librarianship is that materials should be as accessible to users as possible. The prevailing practice in regard to this principle was a moot point during a recent visit of an accrediting committee to our library. This focused attention on the question of open or closed stacks in libraries of colleges and teacher training institution having less than I,OOO students.
\end{abstract}

Library Literature was consulted, but nothing was found that would shed much light on the problem. In the ten-year period from 1943 to 1953 , only six entries were found which dealt with the subject "Access to Shelves." In all cases the articles were not concerned with practices in American academic libraries.

A questionnaire was therefore prepared and mailed to 83 libraries of Group III Colleges (with a library budget of under $\$ 3 \mathrm{I}, \mathrm{OOO})$ and Teacher-Education Institutions with less than I,OOO students selected from the I95I-52 "College and University Statistics" given in the January 1953 issue of COLLEGE AND RESEARCH LibRARIES. The response was most satisfactory. Of 83 questionnaires sent out, 69 , or $83 \%$, were returned. The data which were derived -from the questionnaire should be regarded only as facts of actual practice and not as a defense or condemnation of either open or closed stack systems.

The 69 colleges have an average enrolment of 623 students; of the 69 libraries answering, $52(75 \%)$ have open stacks, and I7 (25\%) have closed stacks. One

JULY, 1954 returned questionnaire marked as a closed stack library was not usable.

TABLE I

Enrollment of Colleges With Open and Closed Stack Libraries

\begin{tabular}{l|c|c|c|c}
\hline \hline & High & Low & Average & $\begin{array}{c}\text { No. of } \\
\text { Libraries }\end{array}$ \\
\cline { 2 - 3 } Open Stacks & 989 & 278 & 609 & 52 \\
\hline Closed Stacks & 992 & 329 & 653 & I7 \\
\hline
\end{tabular}

\section{Open Stacks}

The popularity of open stacks seems to be founded on the following sentiment, as stated by a librarian: "Our policy, in general, is to eliminate as many barriers between the book and readers as possible." This policy seems to be adhered to since only I 2 of the 52 open stack libraries exercise any control over the passage of patrons into and out of the stack area. These I 2 use one control desk. Ten use student assistants, one a clerical, and one a professional at the control desk. Twenty-one libraries reported the existence of a control desk but only i 2 do any checking. All but one of the libraries have no restrictions on what materials or possessions can be taken into the stacks. One library allows only notebooks to be taken into the stacks. Two of the libraries require the students to register when entering the stacks. Thirtyfive of the libraries have either an entrance and an exit or one combined entrance and exit. Seventeen have multiple entrances and/or exits.

Asked how open stacks have affected the number and disposition of the library staff, 30 reported that it is impossible to say. Of the remainder, 13 reported that less staff is 
TABLE II

The Effect of Open Stacks on the Numbers of Staff Members

\begin{tabular}{l|c|c|c|c|c|c}
\hline \hline & $\begin{array}{c}\text { No. of } \\
\text { Libra- } \\
\text { ries }\end{array}$ & Pages & $\begin{array}{c}\text { Circu- } \\
\text { lation } \\
\text { Help }\end{array}$ & $\begin{array}{c}\text { Cleri- } \\
\text { cals }\end{array}$ & $\begin{array}{c}\text { Pro- } \\
\text { fes- } \\
\text { sionals }\end{array}$ & $\begin{array}{c}\text { Stack } \\
\text { Help }\end{array}$ \\
\hline Additional & 9 & 3 & I & 0 & I & 4 \\
\hline Less & I3 & I0 & 4 & 5 & 3 & 4 \\
\hline
\end{tabular}

needed and nine said more is needed. One library which shifted to open stacks responded that a shift in duties was necessary. It found that more shelf reading was necessary and that less time was spent going for books in the stacks.

TABLE III

Collections Separated from the Stack Area

\begin{tabular}{l|c|c|c|c}
\hline & $\begin{array}{c}\text { Docu- } \\
\text { ments }\end{array}$ & $\begin{array}{c}\text { Periodi- } \\
\text { cals }\end{array}$ & $\begin{array}{c}\text { Refer- } \\
\text { ence }\end{array}$ & $\begin{array}{c}\text { Brows- } \\
\text { ing } \\
\text { Room }\end{array}$ \\
\hline Open Stacks & I4 & 37 & 34 & I 2 \\
\hline Closed Stacks & 4 & I3 & I7 & 7 \\
\hline
\end{tabular}

The 52 open stack libraries average 3.88 full time staff. The average for professionals is 2.74 ; for clericals, I.14; for student assistants, II.26. (See Table IV).

In the matter of circulation, eight librarians said that open stacks increase circulation, one said they decrease circulation, and 43 said they had no relevant data. Seven libraries reported that open stacks increase the number of patrons and 45 indicated they could not provide information on this point. Three of the libraries gave statistics on their increase of circulation as $25 \%$, eight and one-half times, and $50 \%$. One library said that circulation decreased but patron use increased.

Thirty-eight of the open stack libraries still give page service and $\mathrm{r} 4$ do not. Ten libraries give page service to non-college users.

Twenty-eight of the libraries reported that they have no figures available on percentage of book loss. Twenty-three indicated that their losses are between zero and $5 \%$ and one said between $5 \%$ and $10 \%$. One library reported the loss of 87 I titles, out of $3 \mathrm{I}, \mathrm{I} I 2$ total volumes, during the period from 1925 to 1952 . Another library reported $.08 \%$ loss for the period from r 94 I to 1948 .

Only two libraries reported that they are planning changes in the policy of open stacks. A librarian in a library which has always had open stacks stated: "We are now planning a new library and thinking seriously of having closed stacks. With open stacks we find it hard to keep books in proper place; also, we find we lose quite a number." The other library reported that they plan closer control at the main entrance.

In answer to the question, "How long has your library had open stacks?" it was found that 33 have always had open stacks, nine less than five years, three between six and ten years, one between eleven and fifteen years, one between sixteen and twenty years, and five over twenty-one years.

In addition to having open stacks, 15 libraries have recreational reading rooms. In handling periodicals, i 5 libraries have only the current issues on open shelves and

TABLE IV

Personnel of Open and Closed Stack Libraries

\begin{tabular}{|c|c|c|c|c|c|c|c|c|c|c|c|c|}
\hline & \multicolumn{3}{|c|}{ Professional } & \multicolumn{3}{|c|}{ Clerical } & \multicolumn{3}{|c|}{$\begin{array}{l}\text { Student } \\
\text { Assistants }\end{array}$} & \multicolumn{3}{|c|}{$\begin{array}{l}\text { Full Time } \\
\text { Staff }\end{array}$} \\
\hline & High & Low & Aver. & High & Low & Aver. & High & Low & Aver. & High & Low & Aver \\
\hline Open & 6 & I & 2.74 & $3 \cdot 5$ & $\circ$ & I. I4 & 30 & $\circ$ & II. 26 & 7 & 2 & 3.88 \\
\hline Closed & 3 & I & 2.31 & 2.0 & $\circ$ & .70 & 22 & 5 & II .58 & 5 & 2 & 3.01 \\
\hline
\end{tabular}


37 libraries have both current and bound copies on open shelves. All but one library have all reference books on open shelves. It was found that 19 of the 52 libraries have an open shelf reserve collection, and I2 have departmental or divisional collections. A few libraries have collections outside the library, four have classroom collections, six have dormitory collections, and two have fraternity or sorority collections.

Four of the open stack libraries have budgets over \$3I,Ooo. They have an average enrolment of 67I students. Two are Group III Colleges and two are Teachers Colleges.

\section{Closed Stacks}

Of the I 7 libraries with closed stacks, 4 reported that a change was being considered; the others indicated satisfaction with present arrangements. Among the more frequent reasons given for not opening stacks were the following: possibility of increased staff costs, current architectural difficulties, and anticipated serious loss of books. A librarian of an institution which had shifted from open to closed stacks gave the following as its reason: "The closing of stacks seem justified because we felt that open stacks contributed to a general slacking in the systematic use of the library which seems a proper contribution of the library to undergraduate students. In short, there seemed to be too many students seeing just what the library happened to have on the shelf and not really learning what the resources are through proper conjunctive use of the card catalog and bibliographies." This librarian added that the faculty and students resented the change to closed stacks and that their new building will have completely open facilities but with provision for shutting the stacks off wholly, or in part, if need for a change is seen. Another librarian said that there was enough mis-shelving by faculty and pages without allowing general freedom in the stacks. (The question was raised as to the wisdom of spending funds on creating a good card catalog if users are going to get what they want by going directly to shelves!) The other three librarians who are thinking of changing to open stacks are waiting for new facilities.

The closed stack libraries have some provisions for direct use of materials by students. These include recreational reading rooms, periodical collections, changing circulating collections, reserve collections, and departmental and divisional collections. One library has provision for direct student use by classroom collections, two by dormitory collections, and one by fraternity and sorority deposits. For the tabulation of collections separate from the stacks area see Table III.

In the matter of book loss, eight libraries have a zero to $5 \%$ loss and the remaining closed stack libraries said that no figures are available. One library reported that it keeps an accurate record of losses. The loss figure is .or of one per cent. Another library reported: "We had open stacks but our loss was heavy so we returned to closed stacks with permits." When asked for the loss figure as an open stack library, their answer was .002 per cent. This was 6I titles out of a book stock of 25,000 volumes for the year I950 which was their last year with open stacks.

The closed stack libraries have an average full time staff of 3.0I. The professionals average $2.3 \mathrm{I}$, the clericals, .7 , and student assistants, I I.58. One library, that of a teachers college, has a budget over $\$ 31,000$.

\section{Conclusions}

According to the answers of the questionnaire, the popularity of open stacks for colleges under I,OOO students seems to be established.

Open stack libraries with control over the passage of patrons from the stacks are 
in a minority. Without more exact figures as to book loss, it is difficult to judge whether patrons coming out of the stacks should be checked. Two open stack libraries that reported exact data have a low book loss. One may speculate what the picture would be if every library kept exact figures on book loss as compared to total volumes. A two per cent loss in a college library of 50,000 volumes means a loss of I, ooo books. When replacement costs are considered, a small percentage loss could be quite serious.

There seems to be no clear indication of an increase or decrease of circulation with open stacks.

A most important fact brought out by the questionnaire is the absence of sufficient data on which to base definite conclusions of the merits of open or closed stacks.

Results of the questionnaire indicate that there is divided opinion on the number of personnel needed by an open stack library. Local conditions may directly affect the size of staff.

Colleges with open stack libraries average 609 students. Colleges with closed stack libraries average 653 students. Yet the libraries with open stacks average approximately one more full time person, 3.88 as against 3.01. Also 38 out of 52 open stack libraries still give page service. It would seem that page service could be dispensed with when the stacks are opened to patrons, but this does not seem to be true in the majority of the open stack libraries. A library that changed to open stacks recently reported that it found that there had to be a shift in duties but no decrease in staff.

From the answers given to the questionnaire, there is a trend toward unrestricted or freer use of periodicals.

Another interesting point brought out by the questionnaire is that 23 out of 69 libraries have reserve books on open shelves.

The significant fact brought out by this survey of the libraries of colleges with less than 1,000 students is that regardless of whether a library has open or closed stacks, librarians are generally thinking in terms of a freer use of materials. This trend seems to warrant the prediction that the practice of open stacks will be extended in accordance with such thinking.

\section{The Farmington Plan}

\section{(Continued from page 284)}

that there is foundation for the second interpretation.

Should the Farmington Plan consider removing any of its intentional exclusions? Periodicals did not appear at all in this study, and so no suggestion can be offered. Dissertations and textbooks did appear, but to no considerable extent. These categories are under discussion for inclusion, and it seems probable that some selection of these will be obtained in the future, if a satisfactory basis for selection can be agreed upon. Government documents are remarkable for their virtual absence, but it would seem that their importance and use in this country might be the subject of further inquiry.

From this brief study of the success of the Farmington Plan acquisition policy, it seems that compliments are due its organizers for so competently covering the field in such a short span of time. However, this study indicates the desirability of anothermuch more difficult to conduct-into the actual source of the needed research books which are supplied to research workers. In short, the opposite of the present inquiry would be valuable as a positive approach. 